\title{
Accommodation in phakic and pseudophakic eyes measured with subjective and objective methods
}

\author{
Gabor Nemeth, MD, PhD, Agnes Lipecz, MD, Eszter Szalai, MD, PhD, \\ Andras Berta, MD, PhD, DSci, Laszlo Modis Jr, MD, PhD, DSci
} PURPOSE: To measure accommodation subjectively and objectively and assess anterior segment
changes during accommodation in phakic eyes and pseudophakic eyes.

\begin{abstract}
SETTING: Department of Ophthalmology, Medical Health and Science Centre, University of Debrecen, Debrecen, Hungary.
\end{abstract}

DESIGN: Case series.

METHODS: Subjective and objective accommodation measurements and pupillometry were performed in phakic and pseudophakic patients. Refraction and pupil diameter were recorded with different accommodation stimuli. Corneal higher-order aberrations (HOAs) and anterior chamber depths (ACDs) were detected with a rotating Scheimpflug camera.

RESULTS: The mean age of the 44 patients in the phakic group was 36.34 years \pm 16.6 (SD) and of the 27 patients in the pseudophakic group, $69.3 \pm 9.98$ years. The mean subjective accommodation was $4.49 \pm 3.48$ diopters (D) in phakic eyes and showed significant correlation with age, spherical aberration, changes in pupil diameter, and ACD. The mean subjective accommodation was $0.50 \pm 0.28 \mathrm{D}$ in pseudophakic eyes. In phakic eyes, the mean objective accommodation was $0.46 \pm 1.02 \mathrm{D}, 1.06 \pm 1.33 \mathrm{D}$, and $2.2 \pm 1.9 \mathrm{D}$ with $2.0 \mathrm{D}, 3.0 \mathrm{D}$, and $5.0 \mathrm{D}$, respectively, of stimulus. In pseudophakic eyes, measurable objective accommodation was recorded. In phakic eyes, the correlations were significant between these values and age, changes in ACD, pupil size, and corneal spherical aberration. In pseudophakic eyes, the only correlation was with the spherical equivalent value.

CONCLUSIONS: The magnitude of accommodation was greater with subjective measures than objective measures. In pseudophakic eyes, senile miosis and HOAs can be regarded as underlying factors in subjective accommodation; however, objective accommodation is not clinically significant.

Financial Disclosure: No author has a financial or proprietary interest in any material or method mentioned.

J Cataract Refract Surg 2013; $\mathbf{\square}: \mathbf{\square}$ (c) 2013 ASCRS and ESCRS

The accommodation of a human eye involves an increase in the dioptric power when focusing on a near object. Several controversial theories on the accommodative process have been proposed. ${ }^{1-3}$ At present, one of the greatest challenges in ophthalmology is to restore the significantly declining and finally ceasing accommodation in presbyopic eyes by surgical means. It is of great importance to measure accommodation and to distinguish between subjective accommodation and objective accommodation. This allows assessment of the surgical effects on presbyopia ${ }^{4,5}$ and of the effects of different intraocular lens (IOL) types. To gain a full understanding of the accommodative process in the long run, an accurate, repetitive, and reliable measurement is indispensable. Accommodation measurements can be performed using subjective $^{6,7}$ and objective ${ }^{8-10}$ methods. Our goal was to evaluate and compare the amplitude of accommodation and changes in pupil size measured subjectively and objectively with a binocular open-field autorefractor/keratometer in phakic eyes and pseudophakic eyes and to observe anterior segment changes during accommodation using Scheimpflug imaging.

\section{PATIENTS AND METHODS}

In this study, all procedures adhered to the tenets of the Declaration of Helsinki and were approved by a local ethics committee. All participants provided informed consent. The 
inclusion criteria were a spherical refractive error less than 3.0 diopters (D) and a cylindrical refractive error less than $2.0 \mathrm{D}$ in both eyes, no previous intraocular surgery except cataract surgery, and contact lens use.

Before the accommodation measurements in each eye, the subjective refractive error was tested. Then, the keratometry, axial length (AL), and anterior chamber depth (ACD) were assessed using 3 repeated measurements with partial coherence interferometry (PCI) (IOLMaster, software version 5.4, Carl Zeiss Meditec AG). When the keratometric data were evaluated, the degree of corneal astigmatism was defined as against the rule (ATR) when the steeper corneal curvature measured between 0 degree and 30 degrees and between 150 degrees and 180 degrees, oblique when the steeper corneal curvature measured between 30 degrees and 60 degrees and between 120 degrees and 150 degrees, and with the rule (WTR) when the steeper corneal curvature measured between 60 degrees and 120 degrees. Three tests were performed in the order shown below.

\section{Method 1: Subjective Accommodation Test}

Under standard room illumination (Eurolite Luxmeter LM-50) and mesopic conditions (ranging from 5 to 15 lux), the patient was seated with a full-distance refractive correction while viewing the smallest letter representing a $100 \%$ correct response on the visual acuity chart. Next, gradually increasing minus-power lenses in $0.25 \mathrm{D}$ steps were added (minus-lenses-to-blur method), thus stimulating and measuring accommodation, until the patient was unable to recognize the letter representing $100 \%$ visual acuity. This added diopter was defined as the amplitude of accommodation.

\section{Method 2: Objective Accommodation Test and Pupillometry}

Measurements were performed with a WAM-5500 binocular autorefractor/keratometer (Grand Seiko Co., Ltd.). The device is an open-field autorefractor with an infrared pupillometry function. The patient was seated with his or her head supported and looked at a real target through a view window with both eyes. The fixation point is not a built-in light source as in most ophthalmology equipment. The distant refractive state was obtained and the pupil size measured by asking the patient to fixate on a target (a black star on a white sheet) placed $5 \mathrm{~m}$ from the window. For measurements at a near viewing distance, the patient looked at the target of a black star on a white sheet hanging from the ruler attached to the upper part of the window at $50 \mathrm{~cm}, 33 \mathrm{~cm}$, and $20 \mathrm{~cm}$.

During examination, the patient viewed stimuli binocularly; however, only 1 eye was examined at a time and the patient was unaware of which eye was being examined.

Submitted: January 25, 2013.

Final revision submitted: April 9, 2013.

Accepted: April 9, 2013.

From the Department of Ophthalmology, Medical and Health Science Center, University of Debrecen, Debrecen, Hungary.

Corresponding author: Gabor Nemeth, MD, PhD, Department of Ophthalmology, University of Debrecen, Nagyerdei Boulevard 98, H-4012 Debrecen, Hungary. E-mail: nemeth222@yahoo.com.
During the examination, the operator kept the pupil in focus on the screen with the help of the joystick. Measurements were obtained automatically in the case of centrally adjusted pupils. In each case, 3 repeated measurements were taken with the adjustments; that is, there was a sensitivity of 0.01 $\mathrm{D}$ and $0.0 \mathrm{~mm}$ vertex distance for measured refractions. Refractive results (spherical and cylindrical with axis) and pupil sizes were also recorded for further calculations. The lighting in the examination room ranged between 5 lux and 15 lux at the eye level and was measured with the lux meter.

\section{Method 3: Measurement of Anterior Segment Parameters and Changes}

Three images were obtained for each eye with the highresolution Pentacam HR device (Oculus Optikgeräte $\mathrm{GmbH})$. The device is based on the rotating Scheimpflug imaging technique with a distant $0.0 \mathrm{D}$ adjustment in $25 \mathrm{im}-$ ages/sec mode. The red, flashing circle target of the device was modified by the built-in diopter scale, as described previously. ${ }^{11}$ This adjusted power is required for the ocular focusing of the target with the accommodation. The patient was instructed to focus on the target continuously while the camera was rotating and capturing the images. Three images were also obtained with $2.0 \mathrm{D}, 3.0 \mathrm{D}$, and $5.0 \mathrm{D}$ of stimuli. The following data were recorded for further calculations: the ACD, corneal total root mean square (RMS), corneal higher-order aberrations (HOAs) RMS, and spherical aberration of the cornea.

In the pseudophakic group, measurements were taken after aspheric monofocal IOL (Ar40e, Abbott Medical Optics, Inc.) implantation at least half a year after surgery and after the refraction was considered stable. The same experienced ophthalmologist performed each measurement.

\section{Statistical Analysis}

Statistical analysis was performed with Medcalc software (version 10.0, Medcalc Software). Descriptive statistical results were described as the mean, standard deviation (SD), and $95 \%$ confidence interval (CI) of the mean. The normality of the data was assessed using the Kolmogorov-Smirnov test. If the normality was rejected $(P<.05)$, a nonparametric test was used. The Mann-Whitney $U$ test was used for comparisons between groups or variables and the Spearman rank test for the correlation. A $P$ value less than .05 was considered statistically significant. Bland-Altman plots were created to estimate the agreement between measurement techniques, and the $95 \%$ limits of agreement (LoA) were calculated as the mean $\pm 1.95 \mathrm{SD}$ of the difference. On the Bland-Altman graphs, the central line represents the mean of the intraindividual differences and the broken lines represent the 95\% LoA.

\section{RESULTS}

Forty-four phakic patients and 27 pseudophakic patients were examined in the study. The mean age was 36.34 years \pm 16.6 (SD) ( $95 \%$ CI, 32.8 to 39.8 ; range 19 to 75 years) in the phakic group and $69.3 \pm 9.98$ years (95\% CI, 66.54 to 72.05 ; range 20 to 84 years) in the pseudophakic group $(P<.01)$. The mean AL measured by PCI was $23.41 \pm 1.02 \mathrm{~mm}(95 \% \mathrm{CI}$, 
23.192 to 23.63 ; range 21.34 to $26.37 \mathrm{~mm}$ ) in the phakic group and $23.16 \pm 1.14 \mathrm{~mm}$ (95\% CI, 22.84 to 23.47 ; range 21.16 to 26.3) in the pseudophakic group $(P=.63)$. The mean ACD measured by PCI was $3.43 \pm 0.41 \mathrm{~mm}(95 \% \mathrm{CI}, 3.34$ to 3.52 ; range 2.17 to $4.33 \mathrm{~mm}$ ) in the phakic group. In the phakic group, WTR astigmatism was identified in 73 cases $(82.9 \%)$, ATR in 4 cases $(4.6 \%)$, and oblique in 11 cases $(12.5 \%)$. In the pseudophakic group, WTR was found in 27 cases $(50.0 \%)$, ATR in 17 cases $(31.5 \%)$, and oblique in 10 cases (18.5\%). No correlation was found between the amplitude of subjective accommodation and the direction of astigmatism $(P=.28$, analysis of variance [ANOVA]).

\section{Method 1: Subjective Accommodation Test}

The mean subjective accommodation in phakic eyes was $4.49 \pm 3.48 \mathrm{D}(95 \% \mathrm{CI}, 3.74-5.24$; range 0.0 to $12.0 \mathrm{D})$. It was significantly correlated with age $(r=-0.8, P<.001)$, corneal spherical aberration $(r=-0.25, P=.02)$, resting pupil diameter $(r=0.46$, $P<.001)$, and ACD $(r=0.41, P<.001)$ as well as with the changes in pupil diameter $(r=-0.25, P=.01)$ and $\operatorname{ACD}(r=-0.39, P<.001)$ during accommodation.

The mean subjective accommodation in pseudophakic eyes was $0.50 \pm 0.28 \mathrm{D}(95 \% \mathrm{CI}, 0.42-0.58$; range 0.0 to $1.0 \mathrm{D}$ ). There were no significant correlations with any parameter mentioned above.

\section{Method 2: Objective Accommodation Measurement and Pupillometry}

In phakic eyes, the mean objective accommodation was $0.46 \pm 1.02 \mathrm{D}$ with $2.0 \mathrm{D}$ of stimulus, $1.06 \pm$ $1.33 \mathrm{D}$ with $3.0 \mathrm{D}$ of stimulus, and $2.2 \pm 1.9 \mathrm{D}$ with

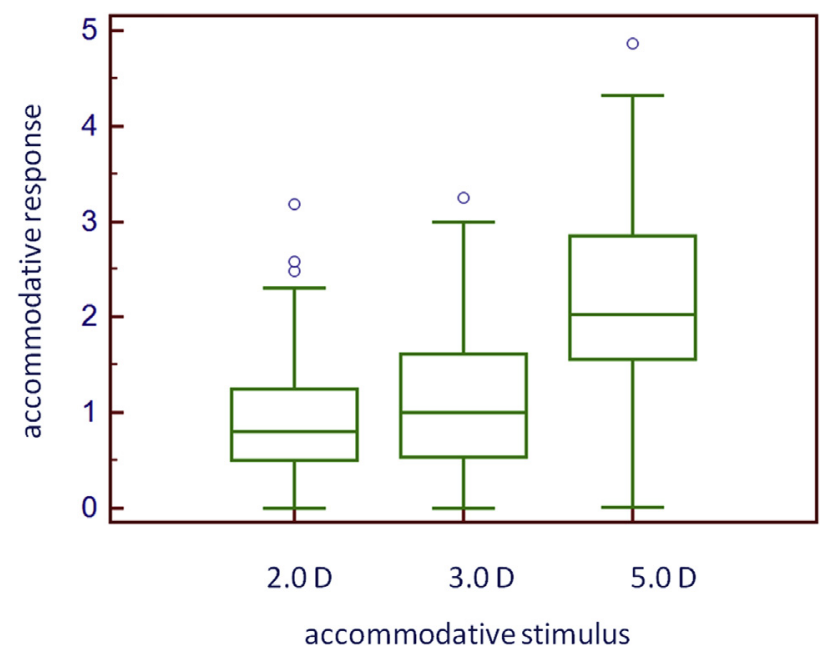

Figure 1. Objective accommodation values with $2.0 \mathrm{D}, 3.0 \mathrm{D}$, and $5.0 \mathrm{D}$ of stimuli measured with the autorefractor/keratometer in phakic eyes $(P=.01$, ANOVA).
5.0 D of stimulus $(P<.001$, ANOVA) (Figure 1$)$. There was a correlation between these values and age $(r>0.7, P<.001)$; the magnitude of astigmatism $(r>0.4, P<.001)$; resting ACD $(r<-0.5, P<.001)$; total RMS cornea $(r>0.25, P<.01)$; changes in ACD $(r>0.3, P<.01)$, pupil size $(r>0.25, P<.01)$, and corneal spherical aberration $(r>0.35, P<.001)$; and spherical aberration changes detected during accommodation $(r<-0.3, P<.01)$.

In pseudophakic eyes, the mean objective accommodation was $0.23 \pm 0.4 \mathrm{D}$ with $2.0 \mathrm{D}$ of stimulus, $0.13 \pm$ $0.5 \mathrm{D}$ with $3.0 \mathrm{D}$ of stimulus, and $0.12 \pm 0.5 \mathrm{D}$ with $5.0 \mathrm{D}$ of stimulus $(P=.55$, ANOVA) (Figure 2). The rate of objective accommodation with induced stimuli exceeded $0.50 \mathrm{D}$ in 8 pseudophakic cases $(29.6 \%)$; these eyes also showed higher subjective accommodation (mean $0.69 \pm 0.53 \mathrm{D}$ ). Regarding objective accommodation, no significant correlation was found with the parameters mentioned above. However, a correlation with spherical aberration values was seen $(r>0.3$, $P<.001)$.

The mean resting pupil diameter was $5.54 \pm$ $1.03 \mathrm{~mm}$ (95\% CI, 5.31 to 5.78; range 2.9 to $7.6 \mathrm{~mm}$ ) in phakic eyes and $3.94 \pm 0.86 \mathrm{~mm}(95 \% \mathrm{CI}, 3.69$ to 4.19; range 2.5 to $5.8 \mathrm{~mm})$ in pseudophakic eyes $(P<.001)$. With a full $5.0 \mathrm{D}$ of stimulus, the mean changes in pupil diameter were $-0.69 \pm 0.74 \mathrm{~mm}$ ( $95 \% \mathrm{CI},-0.85$ to -0.52 ; range -3.2 to $0.8 \mathrm{~mm}$ ) in phakic eyes and $-0.9 \pm 1.46 \mathrm{~mm}(95 \% \mathrm{CI},-1.33$ to -0.47 ; range $-5.60 \mathrm{~mm}$ to $0.93 \mathrm{~mm}$ ) in pseudophakic eyes $(P=.26)$.

The subjective method significantly overestimated the amplitude of accommodation measured objectively in phakic eyes and in pseudophakic eyes. Moreover, the results of both methods correlated well

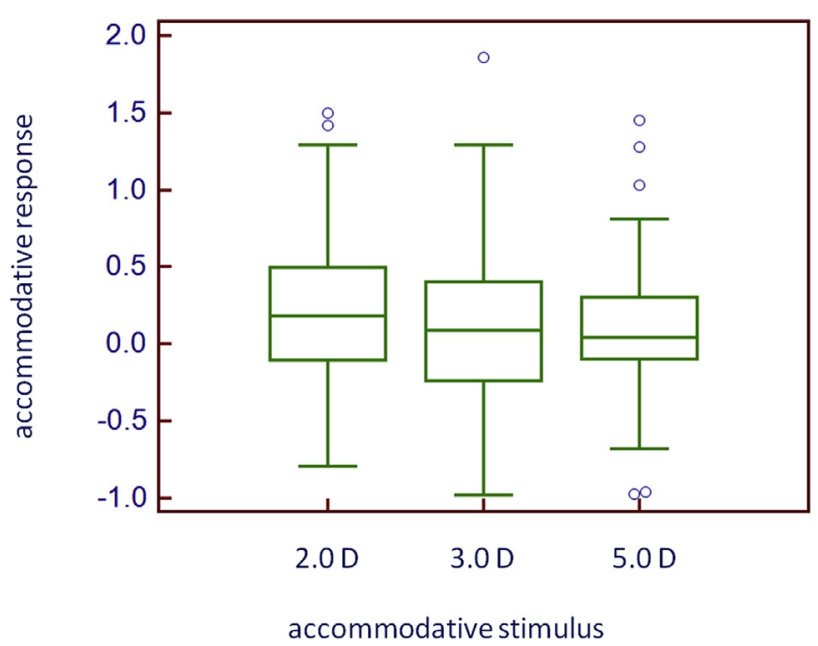

Figure 2. Objective accommodation values with $2.0 \mathrm{D}, 3.0 \mathrm{D}$, and $5.0 \mathrm{D}$ of stimuli measured with the autorefractor/keratometer in pseudophakic eyes $(P=.55$, ANOVA). 


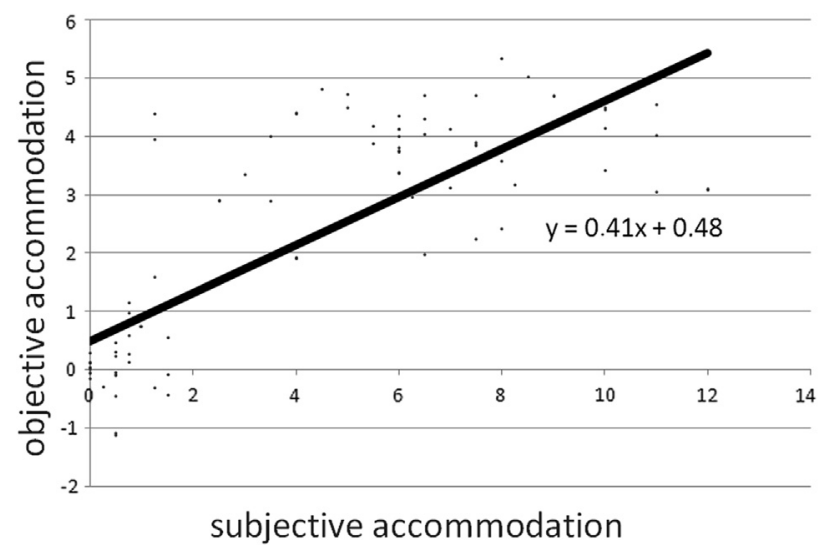

Figure 3. Correlation between subjective and objective accommodation based on Spearman correlation in phakic eyes $(r=0.76$, $P<.001)$.

in phakic eyes $(r=0.76, P<.001)$ (Figure 3) and showed no statistically significant correlation in pseudophakic eyes $(r=0.05, P=.73$ ) (Figure 4). Nonetheless, a comparison of the 2 methods showed good agreement (Figures 5 and 6).

The mean accommodative lag was $2.68 \pm 2.28 \mathrm{D}$ (95\% CI, 2.19 to 3.17; range 0.0 to $9.2 \mathrm{D}$ ) in the phakic group and $4.93 \pm 0.68 \mathrm{D}(95 \% \mathrm{CI}, 4.74$ to 5.12 ; range 3.20 to $7.02 \mathrm{D})$ in the pseudophakic group $(P<.001)$. Its value correlated well with age in the phakic group $(r=0.85, P<.001)$ and was borderline significant in the pseudophakic group $(r=0.26, P=.05)$.

\section{Method 3: Measurement of Anterior Segment Parameters and Changes}

The mean change in ACD measured with the rotating Scheimpflug camera during the entire

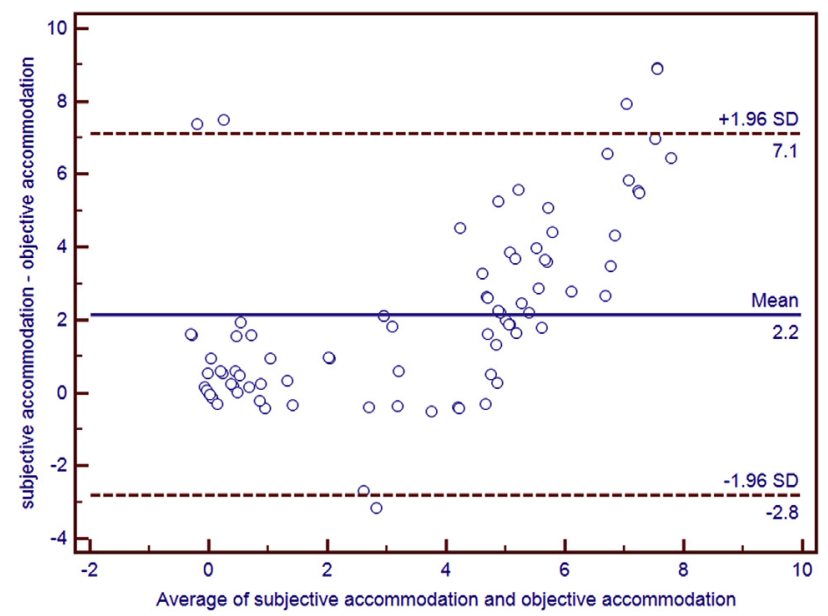

Figure 5. Difference in accommodation response measurements between subjective (minus-lenses-to-blur) and objective (autorefractor/keratometer) techniques against their mean in the phakic group (Bland-Altman plot).

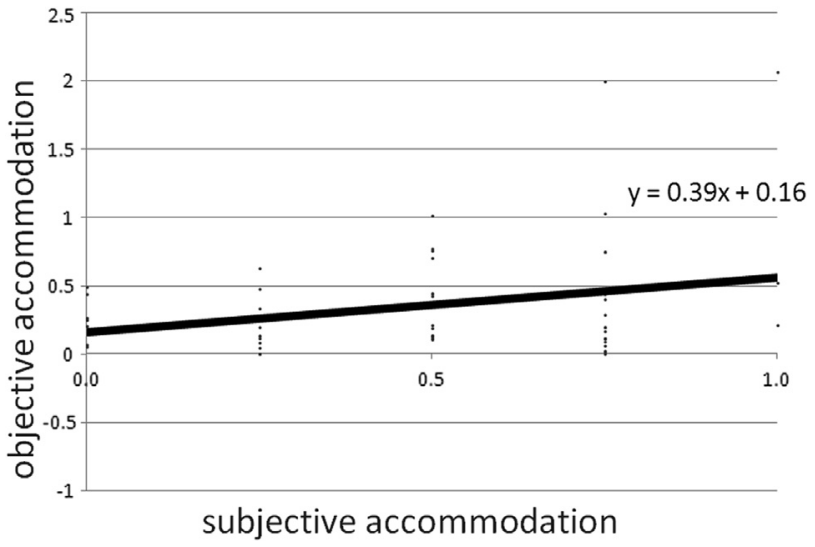

Figure 4. Correlation between subjective and objective accommodation based on Spearman correlation in pseudophakic eyes $(r=0.05, P=.73)$.

accommodation process was $-0.02 \pm 0.05 \mathrm{~mm}(95 \%$ $\mathrm{CI},-0.03$ to -0.01 ; range 0.05 to $-0.25 \mathrm{~mm})$ in the phakic group and $-0.04 \pm 0.19 \mathrm{~mm}(95 \% \mathrm{CI}$, 0.19 to -0.5 ; range -0.50 to $0.43 \mathrm{~mm}$ ) in the pseudophakic group $(P=.28)$. In 15 pseudophakic cases $(27.7 \%)$, an effective IOL shift of more than $0.3 \mathrm{~mm}$ was observed.

In phakic eyes, the mean corneal total RMS was 1.82 $\pm 1.05 \mu \mathrm{m}(95 \% \mathrm{CI}, 1.6$ to 2.05 ; range 0.78 to $6.80 \mu \mathrm{m})$ at distance vision and $1.74 \pm 0.64 \mu \mathrm{m}(95 \% \mathrm{CI}, 1.6$ to 1.88; range 0.72 to $5.46 \mu \mathrm{m})$ at near vision with a $5.0 \mathrm{D}$ stimulus $(P=.45)$. The RMS value was statistically significantly higher in pseudophakic eyes than in phakic eyes $(P<.001)$. At distance vision, the mean total corneal RMS was $3.15 \pm 2.18 \mu \mathrm{m}(95 \% \mathrm{CI}, 2.55$ to 3.75; range 1.01 to $11.88 \mu \mathrm{m}$ ) and at near vision with $5.0 \mathrm{D}$ of stimulus, $2.97 \pm 1.82 \mu \mathrm{m}(95 \% \mathrm{CI}, 2.44$ to 3.49; range 0.91 to $7.50 \mu \mathrm{m})(P=.51)$.

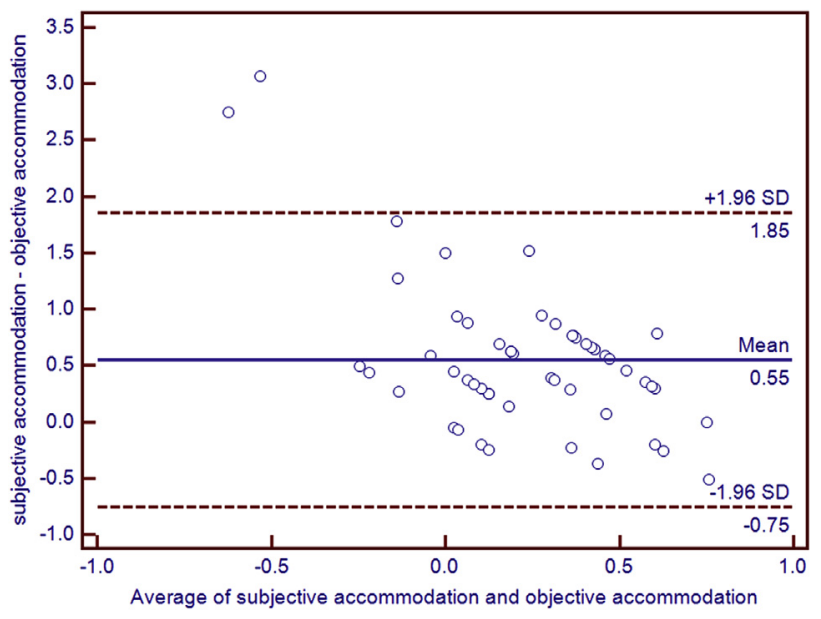

Figure 6. Difference in accommodation response measurements between subjective (minus-lenses-to-blur) and objective (autorefractor/keratometer) techniques against their mean in the pseudophakic group (Bland-Altman plot). 
The corneal HOA RMS values were statistically significantly higher in pseudophakic eyes than in phakic eyes $(P<.001)$. The mean total corneal HOA RMS in phakic eyes was $0.38 \pm 0.19 \mu \mathrm{m}(95 \% \mathrm{CI}, 0.34$ to 0.42 ; range 0.17 to $1.85 \mu \mathrm{m}$ ) at distance vision and $0.39 \pm 0.27 \mu \mathrm{m}(95 \% \mathrm{CI}, 0.33$ to 0.46 ; range 0.16 to $2.10 \mu \mathrm{m})$ at near vision with $5.0 \mathrm{D}$ of stimulus $(P=.45)$. In pseudophakic eyes, the mean total corneal HOA RMS was $0.94 \pm 0.83 \mu \mathrm{m}(95 \% \mathrm{CI}, 0.71$ to 1.17 ; range 0.24 to $4.50 \mu \mathrm{m})$ at distance vision and $0.87 \pm$ $0.68 \mu \mathrm{m}$ (95\% CI, 0.68 to 1.06; range 0.24 to $3.24 \mu \mathrm{m}$ ) at near vision with $5.0 \mathrm{D}$ of stimulus $(P=.65)$.

The mean spherical aberration in phakic eyes was $0.78 \pm 0.35 \mu \mathrm{m}$ (95\% CI, 0.71 to 0.86 ; range 0.16 to $2.61 \mu \mathrm{m})$ at distance vision and $0.75 \pm 0.31 \mu \mathrm{m}$ with $5.0 \mathrm{D}$ of stimulus at near vision $(95 \% \mathrm{CI}, 0.68$ to 0.81 ; range 0.01 to $1.73 \mu \mathrm{m})(P=.57)$. The mean spherical aberration in pseudophakic eyes was $0.83 \pm 0.33 \mu \mathrm{m}$ ( $95 \% \mathrm{CI}, 0.74$ to 0.92 ; range 0.23 to $1.74 \mu \mathrm{m}$ ) at distance vision and $0.86 \pm 0.38 \mu \mathrm{m}(95 \% \mathrm{CI}, 0.75$ to 0.97 ; range 0.05 to $2.10 \mu \mathrm{m}$ ) at near vision with $5.0 \mathrm{D}$ of stimulus $(P=.62)$. No deviation was found in spherical aberration values in the phakic or pseudophakic group $(P=.86)$.

\section{DISCUSSION}

Human accommodation is a process whereby the dioptric power gradually increases when viewing a nearby target. In this process, the changes in crystalline lens power are of crucial importance. ${ }^{12}$ The active function of the ciliary muscle ${ }^{13}$ is considered to be one of the conditions necessary for the accommodative process. According to classic theory, the physiological adjustment ability of the lens is regarded as the principal underlying factor; however, the shifting of the lens may also play an important role. ${ }^{1-3,14,15}$ With aging, a change in the shape, size, and position of the lens occurs. ${ }^{16,17}$ The age-related decline and the total ceasing of the accommodation amplitude are called presbyopia. ${ }^{18}$ The restoration of accommodation is one of the greatest challenges in ophthalmology at present. The measurement of accommodation is important when analyzing the effects of various surgical techniques. When performing subjective measurements apart from real accommodation, several other factors play important roles in near vision; these include pupil size, corneal multifocality, and the resulting increased depth of focus. On the other hand, objective measurements of accommodation are always device dependent.

In the present study, we measured refraction alterations and changes in pupil size during accommodation with an open-field autorefractor/keratometer (WAM-5500) in phakic eyes and pseudophakic eyes and compared the data with the results of the subjective test. We also used Scheimpflug analysis to monitor anterior segment changes during the accommodative process.

Studies have found data indicating that there are changes in astigmatism during the accommodative process $^{19,20}$ and that certain wavefront aberration alterations (spherical aberration, coma) can occur. ${ }^{21-25}$ Subjective accommodation measurements in pseudophakic eyes showed a correlation with the proportion of corneal coma-like aberrations. ${ }^{26}$ In our objective measurements, no changes in corneal aberration were observed during accommodation; however, we detected a significantly higher total corneal RMS and total HOA RMS in pseudophakic eyes than in phakic eyes. This deviation is mainly explained by age differences and may also help increase the depth of focus. Miosis, being a member of the accommodative triad, may also significantly influence the effect of HOAs, thus also increasing the depth of focus. In addition, it is well known that the entire eye and corneal HOAs, especially spherical aberration, increase with age, ${ }^{27}$ leading to an increase in the depth of focus. ${ }^{21}$ In our study, HOA RMS and spherical aberration increased with age. Previous studies ${ }^{11,28}$ have evaluated the possible role of corneal pseudoaccommodation. With respect to ocular cyclotorsion, examinations did not confirm changes in the topography of the cornea during accommodation, ${ }^{11,29}$ nor did our study verify such corneal deviations during accommodation.

The most widely used subjective methods for measuring accommodation are the pushup test and the minus-lenses-to-blur test. ${ }^{6,7}$ In the former technique, the patient is tested wearing distance correction; as the target is moved closer to the patient, he or she is instructed to report when the text is no longer in sharp focus. In the latter technique, while the patient is focusing on a distant target, the value of the minus lens at which the target becomes blurry is determined. These methods stimulate and measure accommodation at the same time. Subjective tests seem to overestimate the results obtained with objective tests ${ }^{6,8,9,30-33}$ and are instead used to estimate reading ability. In subjective tests, the increasing effect of the depth of focus of a narrow pupil and of ocular aberrations is added to the active real accommodative power, as is the tolerance against blur perception. This may explain the overall $0.5 \mathrm{D}$ amplitude of subjective accommodation after monofocal IOL implantation in pseudophakic eyes. Our data verified the presence of senile miosis; a significantly narrower pupil was found in pseudophakic eyes, which may support the process of accommodation. We also confirmed the intensified presence of corneal aberrations at an elderly age. It is well 
known that mild ATR myopic astigmatism can be beneficial to uncorrected near acuity in pseudophakic eyes, ${ }^{34}$ although in our smaller cohort of patients, no correlation was found between the subjective accommodation amplitude and the direction of astigmatism.

The real changes in the optical power of the eye are measured by objective tests. Objective accommodation measurements can be performed using Hartinger coincidence refractometry, ${ }^{10}$ wavefront aberrometry, ${ }^{27}$ dynamic retinoscopy, or open-field-of-view autorefractors. ${ }^{35-37}$ Open-field refractometers that apply infrared lights are capable of measuring real binocular physiological accommodation and pupil size changes in real circumstances. During accommodation measurement, if 1 of the eyes is occluded, inaccurate data can be obtained. A study ${ }^{32}$ found that off-axis viewing tests in phakic patients showed very small mean differences due to off-axis viewing. In our study, we used the open-field refractometer to measure 1 eye without occluding the other eye during binocular accommodation. Previous studies found no disparity in the results of different objective measurement techniques ${ }^{9}$ and considered Grand Seiko autorefractors $8,9,38,39$ and certain aberrometers ${ }^{9}$ to be adequately reliable for objectively measuring accommodation. These devices are also capable of measuring dynamic accommodation, which may give further useful information about the characteristics of the accommodative process ${ }^{40}$ and may play an important role when assessing near work-induced discomfort symptoms. ${ }^{41}$

The accommodative response to a stimulus is always smaller than the stimulus itself. The lag of accommodation is denoted as the dioptric value by which, for example, the accommodation during reading is lower than the actual stimulus. Between the ages of 18 years and 22 years, in $69 \%$ of cases with low myopia, the accommodative lag for a $33 \mathrm{~cm}$ target is $1.00 \mathrm{D}$ or more by autorefraction. ${ }^{42}$ The normal value may vary between $0.50 \mathrm{D}$ and $0.75 \mathrm{D}$ in a nonpresbyopic patient ${ }^{43}$ when tested at $40 \mathrm{~cm}$. In addition, in presbyopia, the lag also increases in the case of uncorrected hyperopia or accommodative insufficiency ${ }^{44}$ and the lack of the accommodative lag may suggest latent hyperopia. The response to an accommodative stimulus is affected by the refractive error, ${ }^{45-47}$ refractive error stability, ${ }^{48,49}$ nature of the target, $^{50-52}$ and method of stimulus presentation. ${ }^{45,49}$ We found that the accommodative lag is age dependent in phakic eyes. An age dependency was also observed in pseudophakic eyes; however, it was considered to be weak.

Accommodation can also be measured subjectively and objectively in pseudophakic eyes. ${ }^{53-55}$ In pseu- dophakic eyes, indirect measurements using ultrasonic A-scan measurements ${ }^{56}$ and $\mathrm{PCI}^{53,57}$ before and after ciliary muscle contraction using pilocarpine or phenylephrine found changes in the ACD, suggesting shifting of the IOL. The rate of the shift is highly dependent on the measuring technique and, with these indirect measurements, it is rather the maximum accommodation potential that is being measured. Significant objective accommodation has been neither expected nor observed after standard monofocal IOL implantation. ${ }^{32}$ After implantation of various IOL models, a WR-5100 K autorefractor (Grand Seiko) recorded valid and repeatable refraction values. ${ }^{58}$ We also found that the difference between autorefractor data and the results of the subjective method were nearly constant.

In the pushdown test by Win-Hall and Glasser, ${ }^{32}$ the defocus curves had a range of $2.0 \mathrm{D}$ for a distancecorrected visual acuity of 20/40 or better. With the application of monofocal IOLs, the subjective amplitude of accommodation can vary from 0.42 to $1.08 \mathrm{D}^{53,59}$; however, an accommodation of 1.33 to $2.36 \mathrm{D}$ has also been measured. ${ }^{53,59,60}$ For such a range of subjective amplitudes, the depth of focus and eye aberrations may give an explanation. ${ }^{53,59}$ According to the literature, when an objective measurement is obtained using an autorefractor, the accommodation amplitude is approximately $0.1 \mathrm{D}$ in pseudophakic eyes. $^{32}$ Our results suggest similar, average, and true accommodation. Changes in the ACD during accommodation were minimal in our study, although ACD changes of at least $0.3 \mathrm{~mm}$ were detected in $28 \%$ of our patients. During Pentacam HR examinations, motivation seems to play a more important role in the sense of how much the patient "wants" to get the target in focus and keep it there.

Subjective accommodation and objective accommodation were better in eyes with accommodating IOLs; however, near visual acuity and the subjective and objective amplitudes of accommodation decreased 2 years after IOL implantation. ${ }^{54}$ We performed our measurements after monofocal IOL implantation and during minimal, clinically insignificant objective accommodation of $0.5 \mathrm{D}$; an average subjective accommodation was recorded. No significant correlation was found between subjective accommodation and objective accommodation and the parameters evaluated in pseudophakic eyes with the exception of the spherical equivalent and amount of objective accommodation. As a result of senile miosis in pseudophakic eyes, measurements showed a much narrower pupil and of the parameters evaluated, only the narrower pupil and the higher corneal HOAs may pay a role in the increase in the depth of focus in pseudophakic eyes. 
In summary, our data verify that subjective accommodation is significantly higher than objective accommodation in phakic eyes. The $0.5 \mathrm{D}$ subjective accommodation in pseudophakic eyes can be explained by the combined effect of the pupil miosis-induced increase in the depth of focus and the age-related, significantly higher, corneal aberrations. In pseudophakic eyes, we observed objectively measurable, minimal, and clinically insignificant accommodation with a WAM-5500 autorefractor/ keratometer. The value of this objectively measured accommodation correlated well with the results of the subjective test.

\section{WHAT WAS KNOWN}

- Subjective accommodation is significantly higher than objective accommodation.

- In pseudophakic eyes, no objective accommodation can be observed.

\section{WHAT THIS PAPER ADDS}

- In pseudophakic eyes, $0.5 \mathrm{D}$ of subjective accommodation was measured. This can be explained by the combined effect of the pupil miosis-induced increase in the depth focus and the age-related significantly higher corneal aberrations.

- In pseudophakic eyes, objectively measurable, minimal and clinically insignificant accommodation was observed with an autorefractor/keratometer.

\section{REFERENCES}

1. Helmholtz H. Mechanism of accommodation. In: Southall JPC, ed, Helmholtz's Treatise on Physiological Optics, translated from the third German edition. New York, NY, Dover, 1962; Vol 1, 143-173

2. Tscherning M. Physiologic Optics; Dioptrics of the Eye, Functions of the Retina, Ocular Movements and Binocular Vision, 2nd ed., translated by C. Weiland. Philadelphia, PA, Keystone, 1904; 192-228

3. Schachar RA, Cudmore DP, Torti R, Black TD, Huang T. A physical model demonstrating Schachar's hypothesis of accommodation. Ann Ophthalmol Glaucoma 1994; 26:4-9

4. Mathews S. Scleral expansion surgery does not restore accommodation in human presbyopia. Ophthalmology 1999; 106:873-877

5. Hamilton DR, Davidorf JM, Maloney RK. Anterior ciliary sclerotomy for treatment of presbyopia; a prospective controlled study. Ophthalmology 2002; 109:1970-1976; discussion by RF Steinert, 1976-1977

6. Atchison DA, Capper EJ, McCabe KL. Critical subjective measurement of amplitude of accommodation. Optom Vis Sci 1994; 71:699-706. Available at: http://journals.Iww. com/optvissci/Abstract/1994/11000/Critical_Subjective_
Measurement_of_Amplitude_of.5.aspx. Accessed May 1, 2013

7. Duane A. Normal values of the accommodation at all ages. J Am Med Assoc 1912; 59:1010-1013; also Trans Sect Ophthalmol AMA 1912; 383-391

8. Win-Hall DM, Ostrin LA, Kasthurirangan S, Glasser A. Objective accommodation measurement with the Grand Seiko and Hartinger coincidence refractometer. Optom Vis Sci 2007; 84:879-887. Available at: http://aglasser.opt.uh.edu/ publications/WOK\&G\%200VS\%202007.pdf. Accessed May 1, 2013

9. Win-Hall DM, Glasser A. Objective accommodation measurements in prepresbyopic eyes using an autorefractor and an aberrometer. J Cataract Refract Surg 2008; 34:774-784

10. Fincham EF. The coincidence optometer. Proc Phys Soc (Lond) 1937; 49:456-468

11. Read SA, Buehren T, Collins MJ. Influence of accommodation on the anterior and posterior cornea. J Cataract Refract Surg 2007; 33:1877-1885

12. Young $\mathrm{T}$. The Bakerian Lecture: on the mechanism of the eye. Phil Trans R Soc Lond 1801; 91:23-88. Available at: http://rstl. royalsocietypublishing.org/content/91/23.full.pdf. Accessed May 1, 2013

13. Sheppard AL, Davies LN. In vivo analysis of ciliary muscle morphologic changes with accommodation and axial ametropia. Invest Ophthalmol Vis Sci 2010; 51:6882-6889. Available at: http://www.iovs.org/content/51/12/6882.full.pdf. Accessed May 1, 2013

14. Brown N. The change in shape and internal form of the lens of the eye on accommodation. Exp Eye Res 1973; 15: 441-459

15. Koretz JF, Handelman GH, Brown NP. Analysis of human crystalline lens curvature as a function of accommodative state and age. Vision Res 1984; 24:1141-1151

16. Cook CA, Koretz JF, Pfahnl A, Hyun J, Kaufman PL. Aging of the human crystalline lens and anterior segment. Vision Res 1994; 34:2945-2954

17. Koretz JF, Cook CA, Kaufman PL. Accommodation and presbyopia in the human eye; changes in the anterior segment and crystalline lens with focus. Invest Ophthalmol Vis Sci 1997; 38:569-578. Available at: http://www.iovs.org/cgi/reprint/38/3/ 569.pdf. Accessed May 1, 2013

18. Kleinstein RN. Epidemiology of presbyopia. In: Stark LW, Obrecht G, eds, Presbyopia; Recent Research and Reviews from the Third International Symposium. New York, NY, Professional Press, 1987; 12-18

19. Ukai K, Ichihashi Y. Changes in ocular astigmatism over the whole range of accommodation. Optom Vis Sci 1991; 68:813-818. Available at: http://journals.Iww.com/optvissci/ Abstract/1991/10000/Changes_in_Ocular_Astigmatism_ Over_the_Whole_Range.11.aspx. Accessed May 1, 2013

20. Millodot M, Thibault $C$. Variation of astigmatism with accommodation and its relationship with dark focus. Ophthalmic Physiol Opt 1985; 5:297-301

21. Yeu E, Wang L, Koch DD. The effect of corneal wavefront aberrations on corneal pseudoaccommodation. Am J Ophthalmol 2012; 153:972-981

22. Atchison DA, Collins MJ, Wildsoet CF, Christensen J, Waterworth MD. Measurement of monochromatic ocular aberrations in human eyes as a function of accommodation by the Howland aberroscope technique. Vision Res 1995; 35:313-323

23. He JC, Burns SA, Marcos S. Monochromatic aberrations in the accommodated human eye. Vision Res 2000; $40: 41-48$ 
24. Li Y-J, Choi JA, Kim H, Yu S-Y, Joo C-K. Changes in ocular wavefront aberrations and retinal image quality with objective accommodation. J Cataract Refract Surg 2011; 37:835-841

25. lida $\mathrm{Y}$, Shimizu K, Ito M, Suzuki M. Influence of age on ocular wavefront aberration changes with accommodation. J Refract Surg 2008; 24:696-701

26. Oshika T, Mimura T, Tanaka S, Amano S, Fukuyama M, Yoshitomi F, Maeda N, Fujikado T, Hirohara Y, Mihashi T. Apparent accommodation and corneal wavefront aberration in pseudophakic eyes. Invest Ophthalmol Vis Sci 2002; 43:2882-2886. Available at: http://www.iovs.org/cgi/reprint/ 43/9/2882. Accessed May 1, 2013

27. López-Gil N, Fernández-Sánchez V, Legras R, MontésMicó R, Lara F, Nguyen-Khoa JL. Accommodation-related changes in monochromatic aberrations of the human eye as a function of age. Invest Ophthalmol Vis Sci 2008; 49:17361743. Available at: http://www.iovs.org/cgi/reprint/49/4/1736. Accessed May 1, 2013

28. Yasuda A, Yamaguchi T, Ohkoshi K. Changes in corneal curvature in accommodation. J Cataract Refract Surg 2003; 29:1297-1301

29. Buehren T, Collins MJ, Loughridge J, Carney LG, Iskander DR. Corneal topography and accommodation. Cornea 2003; 22:311-316

30. Ostrin LA, Glasser A. Accommodation measurements in a prepresbyopic and presbyopic population. J Cataract Refract Surg 2004; 30:1435-1444

31. Wold JE, Hu A, Chen S, Glasser A. Subjective and objective measurement of human accommodative amplitude. J Cataract Refract Surg 2003; 29:1878-1888

32. Win-Hall DM, Glasser A. Objective accommodation measurements in pseudophakic subjects using an autorefractor and an aberrometer. J Cataract Refract Surg 2009; 35: 282-290

33. Atchison DA, Charman WN, Woods RL. Subjective depth-offocus of the eye. Optom Vis Sci 1997; 74:511-520. Available at: http://journals.Iww.com/optvissci/Abstract/1997/07000/ Subjective_Depth_of_Focus_of_the_Eye.19.aspx. Accessed May 1,2013

34. Trindade F, Oliveira A, Frasson M. Benefit of against-the-rule astigmatism to uncorrected near acuity. J Cataract Refract Surg 1997; 23:82-85

35. Winn B, Pugh JR, Gilmartin B, Owens H. The effect of pupil size on static and dynamic measurements of accommodation using an infra-red optometer. Ophthalmic Physiol Opt 1989; 9: 277-283

36. McBrien NA, Millodot M. Clinical evaluation of the Canon Autoref R-1. Am J Optom Physiol Opt 1985; 62:786-792

37. Pugh JR, Winn B. Modification of the Canon Auto Ref R1 for use as a continuously recording infra-red optometer. Ophthal Physiol Opt 1988; 8:460-464

38. Win-Hall DM, Houser J, Glasser A. Static and dynamic accommodation measured using the WAM-5500 Autorefractor. Optom Vis Sci 2010; 87:873-882

39. Sheppard AL, Davies LN. Clinical evaluation of the Grand Seiko Auto Ref/Keratometer WAM-5500. Ophthalmic Physiol Opt 2010; 30:143-151

40. Dick HB, Kaiser S. Dynamische Aberrometrie während der Akkommodation phaker Augen sowie Augen mit potenziell akkommodativer Intraokularlinse [Dynamic aberrometry during accommodation of phakic eyes and eyes with potentially accommodative intraocular lenses]. Ophthalmologe 2002; 99:825-834
41. Chase C, Tosha C, Borsting E, Ridder WH III. Visual discomfort and objective measures of static accommodation. Optom Vis Sci 2009; 86:883-889. Available at: http://journals. Iww.com/optvissci/fulltext/2009/07000/visual_discomfort and_objective_measures_of_static.13.aspx. Accessed May 1, 2013

42. Correction of Myopia Evaluation Trial 2 Study Group for the Pediatric Eye Disease Investigator Group. Accommodative lag by autorefraction and two dynamic retinoscopy methods. Optom Vis Sci 2009; 86:233-243. Available at: http://www. ncbi.nlm.nih.gov/pmc/articles/PMC2650735/pdf/nihms70333. pdf. Accessed May 1, 2013

43. Morgan MW Jr. Accommodation and its relationship to convergence. Am J Optom Arch Am Acad Optom 1944; 21:183-195

44. Tosha C, Borsting E, Ridder WH III, Chase C. Accommodation response and visual discomfort. Ophthalmic Physiol Opt 2009; 29:625-633

45. Gwiazda J, Thorn F, Bauer J, Held R. Myopic children show insufficient accommodative response to blur. Invest Ophthalmol Vis Sci 1993; 34:690-694. Available at: http://www.iovs. org/content/34/3/690.full.pdf. Accessed May 1, 2013

46. Nakatsuka C, Hasebe S, Nonaka F, Ohtsuki H. Accommodative lag under habitual seeing conditions: comparison between adult myopes and emmetropes. Jpn J Ophthalmol 2003; 47:291-298

47. McBrien NA, Millodot M. The effect of refractive error on the accommodative response gradient. Ophthalmic Physiol Opt 1986; 6:145-149

48. Allen PM, O'Leary DJ. Accommodation functions: codependency and relationship to refractive error. Vision Res 2006; 46:491-505

49. Gwiazda J, Bauer J, Thorn F, Held RA. Dynamic relationship between myopia and blur-driven accommodation in school-aged children. Vision Res 1995; 35: 1299-1304

50. Schmid KL, Hilmer KS, Lawrence RA, Loh S-Y, Morrish LJ, Brown B. The effect of common reductions in letter size and contrast on accommodation responses in young adult myopes and emmetropes. Optom Vis Sci 2005; 82:602-611. Available at: http://journals.Iww.com/optvissci/Fulltext/2005/ 07000/The_Effect_of_Common_Reductions_in_Letter_Size_ and.14.aspx. Accessed May 1, 2013

51. Johnson CA. Effects of luminance and stimulus distance on accommodation and visual resolution. J Opt Soc Am 1976; 66:138-142

52. Charman WN, Tucker J. Dependence of accommodation response on the spatial frequency spectrum of the observed object. Vision Res 1977; 17:129-139

53. Langenbucher A, Huber S, Nguyen NX, Seitz B, GgusekSchneider GC, Küchle M. Measurement of accommodation after implantation of an accommodating posterior chamber intraocular lens. J Cataract Refract Surg 2003; 29:677-685

54. Wolffsohn JS, Hunt OA, Naroo S, Gilmartin B, Shah S, Cunliffe IA, Benson MT, Mantry S. Objective accommodative amplitude and dynamics with the $1 \mathrm{CU}$ accommodative intraocular lens. Invest Ophthalmol Vis Sci 2006; 47:12301235. Available at: http://www.iovs.org/cgi/reprint/47/3/1230. Accessed May 1, 2013

55. Nakazawa M, Ohtsuki K. Apparent accommodation in pseudophakic eyes after implantation of posterior chamber intraocular lenses: optical analysis. Invest Ophthalmol Vis Sci 1984; 25:1458-1460. Available at: http://www.iovs.org/cgi/reprint/ 25/12/1458.pdf. Accessed May 1, 2013 
56. Vámosi P, Nemeth G, Berta A. Pseudophakic accommodation with 2 models of foldable intraocular lenses. J Cataract Refract Surg 2006; 32:221-226

57. Findl O, Kiss B, Petternel V, Menapace R, Georgopoulos M, Rainer G, Drexler W. Intraocular lens movement caused by ciliary muscle contraction. J Cataract Refract Surg 2003; 29:669-676

58. Wolffsohn JS, Davies LN, Naroo SA, Buckhurst PJ, Gibson GA, Gupta N, Craig JP, Shah S. Evaluation of an open-field autorefractor's ability to measure refraction and hence potential to assess objective accommodation in pseudophakes. Br J Ophthalmol 2011; 95:498-501

59. Küchle M, Nguyen NX, Langenbucher A, GusekSchneider GC, Seitz B, Hanna KD. Implantation of a new accommodative posterior chamber intraocular lens. J Refract Surg 2002; 18:208-216
60. Mastropasqua L, Toto L, Nubile M, Falconio G, Ballone E. Clinical study of the $1 \mathrm{CU}$ accommodating intraocular lens. J Cataract Refract Surg 2003; 29:1307-1312

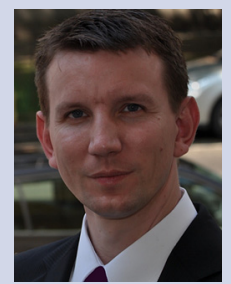

First author:

Gabor Nemeth, MD, PhD

Department of Ophthalmology, Medical and Health Science Center, University of Debrecen, Debrecen, Hungary 